\title{
TEKNOLOGI SMARTPHONE ANDROID DAN APLIKASINYA SEBAGAI PENGENDALI PINTU AIR DAERAH ALIRAN SUNGAI (DAS)
}

\author{
Arianti Kusumawardhani ${ }^{1}$, Shafiq Nurdin ${ }^{2}$, Mokh. Suseno Aji Sari ${ }^{3}$ \\ 1,2Teknik Mesin \\ Politeknik Unisma Malang, Malang, Indonesia \\ e-mail: ${ }^{1}$ arianti.poltekunisma@gmail.com, ${ }^{2}$ shafiq.poltekunisma@gmail.com \\ ${ }^{3}$ Teknik Listrik \\ Politeknik Unisma Malang, Malang, Indonesia \\ e-mail: m.susenoajisari@gmail.com
}

Diterima: 3 Oktober 2017. Disetujui : 19 Nopember 2017. Dipublikasikan : 4 Desember 2017

(C)2017 -TESJ Fakultas Teknik Universitas Maarif Hasyim Latif. Ini adalah artikel dengan akses terbuka di bawah lisensi CC BY 4.0 (https://creativecommons.org/licenses/by/4.0/)

\begin{abstract}
ABSTRAK
Pengoperasian pintu air pada aliran sungai saat ini masih menggunakan sistem manual dengan menggunakan campur tangan tenaga manusia untuk pengendali buka tutupnya. Hal ini mendorong peneliti untuk melakukan penelitian dengan sistem kendali berbasis smartphone berbasis android. Dalam penelitian ini penulis menggunakan smartphone android sebagai sarana untuk kendali pintu air. Smartphone dipilih oleh penulis karena saat ini menjadi alat komunikasi sehari-hari yang mobile di semua kalangan masyarakat sedangkan andriod merupakan sistem operasi yang sebagian besar dipakai pada smartphone tersebut. Smartphone berbasis android akan secara langsung mengendalikan buka tutup pintu Daerah Aliran Sungai (DAS) dengan menggunakan program aplikasi. Masukan dari aplikasi akan memberikan informasi perintah yang diberikan, selanjutnya akan diterima oleh sistem kendali yang terhubung pada mekanisme gerakan mekanik pintu air sungai. Peralatan kendali menggunakan perangkat Arduino Uno yang mampu mengubah signal digital menjadi gerakan mekanik dalam mengoperasikan pintu DAS. Hasil penelitian yang diperoleh, penggunaan perangkat kendali Arduino Uno tidak menyediakan ruang dalam pengelolaan database secara online, maka dibutuhkan software pendukung lainnya untuk mengatasi hal tersebut. Sebagai pengendali dan sistem android merupakan media penghubung informasi saling terkait merupakan sumber informasi yang terbuka.
\end{abstract}

Kata kunci: Pintu air, DAS, aplikasi, Smartphone, Android, Arduino Uno.

\section{PENDAHULUAN}

Menurut UU No. 7 tahun 2004 tentang Sumberdaya Air, Daerah Aliran Sungai (DAS) merupakan suatu wilayah daratan yang satu kesatuan dengan sungai dan anak-anak sungainya, yang berfungsi menampung, menyimpan dan mengalirkan air yang berasal dari curah hujan ke danau atau ke laut secara alami, yang mana batas di darat merupakan pemisah topografis dan batas di laut sampai dengan daerah perairan yang masih terpengaruh aktivitas daratan. Sebagaimana yang telah dinyatakan pada Rencana Tata Ruang Wilayah Nasional (RTRWN) bahwa DAS merupakan bagian yang penting terkait dengan fungsi hidrologi untuk mendukung pengembangan wilayah sekitar, dimana wilayah yang paling tepat bagi pembangu-nan tempat bertemunya berbagai kepentingan. Dari sini Pengelolaan DAS adalah bentuk pengembangan wilayah yang menempatkan DAS sebagai suatu unit pengelolaan sumber daya alam untuk mencapai tujuan peningkatan produksi pertanian dan kehutanan yang optimum dan berkelanjutan (Direktorat Kehutanan Dan Konservasi Sumber Daya Air, Desember 2012).

Dalam dinamika keseimbangan manusia dengan alam bisa berdampak baik atau buruk, tergantung besarnya intervensi manusia terhadap sumberdaya alam dan proses interaksi alam sendiri. Dalam DAS terjadi hubungan timbal balik antara sumberdaya manusia dengan sumberdaya alam yang mempengaruhi kelestarian sumberdaya alam, tidak hanya setempat (onsite) tetapi juga di tempat lain (offsite), sehingga diperlukan sistem pengelolaan menyeluruh dari hulu sampai hilir. (Kementerian Kehutanan, Badan Penelitian dan Pengembangan Kehutanan, 2012)

Salah satu sistem otomasi yang dapat diterapkan adalah buka tutup pintu gerbang secara 
otomatis. Melalui pengembangan sistem otomasi ini penghuni rumah dapat membuka pintu gerbang dari jarak tertentu tanpa harus berinteraksi langsung dengan gerbang tersebut. Perkembangan teknologi yang berkembang menggunakan sistem mikrokontroller Arduino Uno yang diintegrasikan dengan smartphone android melalui modul Bluetooth HC-05, sehingga bisa digunakan sistem buka pintu gerbang tanpa menggunakan cara yang konvensional, namun cukup diakses melalui smartphone android saja (Silvia, Haritman, \& Mulyadi, 2014). Pintu garasi mobil dapat bekerja otomatis dengan model pintu yang dapat menggulung keatas (rolling door). Putaran kerja rolling door menggunakan motor satu fase dan sensor deteksi. Sensor mendeteksi objek yang akan masuk ke garasi kemudian mengirimkan perintah menggerakkan pintu garasi untuk membuka (Wibowo, 2014). Dengan berkembangnya teknologi mikrokontroller saat ini, sistem keamanan dapat dilakukan dengan menggunakan alat elektronik sebagai pengganti sistem keamanan kunci konvensional. Sistem mikrokontroller Arduino Uno yang dapat dimanfaatkan untuk mengontrol relay agar dapat berfungsi melalui input dari keypad berupa kode password untuk membuka dan mengunci sistem keamanan menggunakan solenoid (Guntoro, Somantri, \& Haritman, 2013).

Android merupakan platform open source yang saat ini banyak digunakan pada sebagian besar smartphone di masyarakat. Memiliki keunggulan dalam menyediakan tools dan frameworks yang lengkap untuk pengembangan aplikasi mobile. Sistem android menggunakan database untuk menyimpan informasi penting yang diperlukan agar tetap tersimpan meskipun device dimatikan. Sistem penyimpanan data pada database, sistem android menggunakan SQLite yang merupakan suatu open source database yang cukup stabil dan banyak digunakan pada banyak device berukuran kecil (Setiawan, Andjarwirawan, \& Handojo, 2013).

\section{METODE PENELITIAN}

Metode penelitian dalam menggunakan teknologi smartphone android sebagai pengendali pintu air DAS peralatan pengendali dan mekanik berbasis open source, maka penelitian ini menggunakan metode-metode penelitian sebagai berikut :

a. Studi Literatur. Penelitian ini disusun berdasarkan buku-buku panduan yang mempunyai hubungan dengan permasalahan.

b. Metode Eksperimen. Melakukan pengamatan dan penelitian terhadap sistem mekanik pintu air untuk irigasi dan jumlah debit air yang melintas

c. Metode pengujian. Menguji dan meneliti rangkaian perangkat sistem sistem kontrol pintu DAM dengan interface smartphone android sebagai transmiter dan mikro-kontroller Arduino Uno sebagai received.

Tahapan penelitian seperti pada Gambar 1.

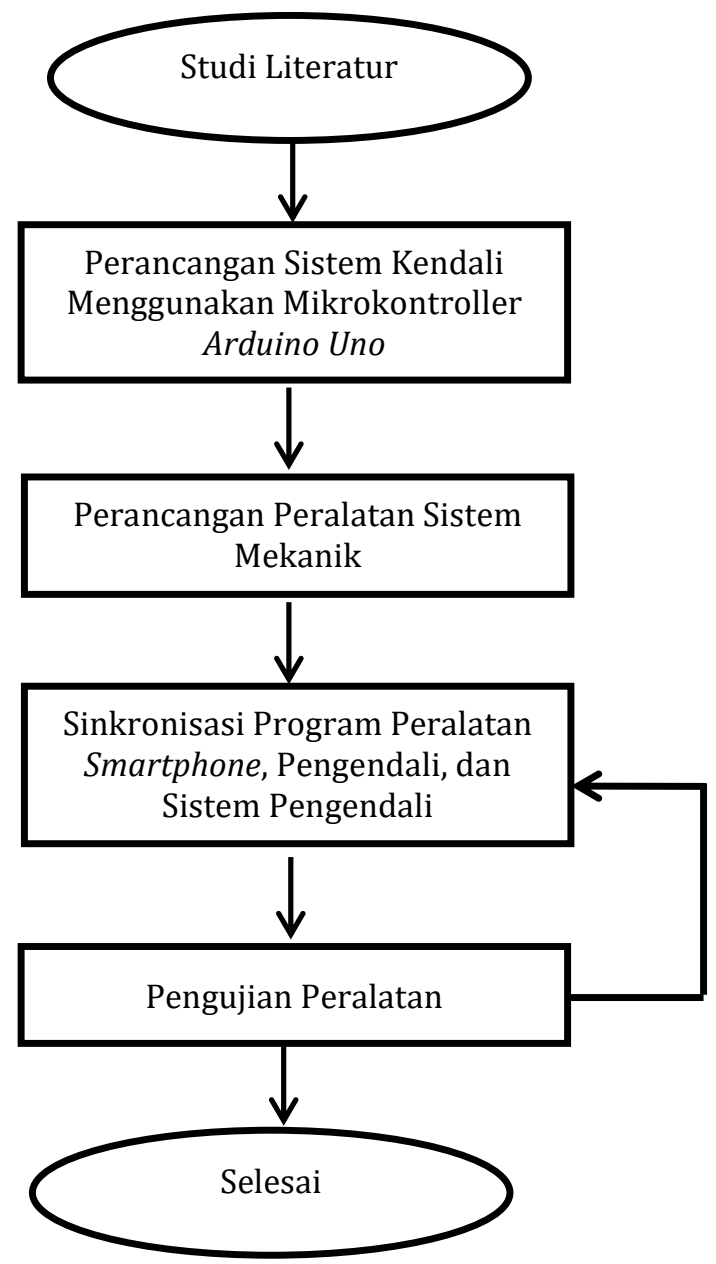

Gambar 1. Flowchart sistem perancangan peralatan

\section{HASIL DAN PEMBAHASAN}

Masukan awal menggunakan smartphone android yang sudah terinstal aplikasi program. Aplikasi ini berfungsi mengirimkan informasi dan perintah ke peralatan pengendali Arduino Uno melalui media cloud. Cloud ini berfungsi sebagai media penyimpanan database. Setelah data informasi dan perintah terkirim ke sistem kendali arduino uno, kemudian diolah informasi dan perintah tersebut untuk menggerakkan peralatan motor. Peralatan pengendali arduino uno terdapat 2 sensor ultrasonic. Sensor ultrasonic yang pertama yaitu sensor ketinggian debit pintu air sedangkan sensor ultrasonic yang kedua sensor ketinggian 
pintu air. Kedua sensor ini di kontrol pada sistem kendali. Sistem kendali Arduino Uno akan mengirimkan data ke smartphone melalui cloud dan selanjutnya data akan dikirimkan ke smartphone sebagai media informasi yang update. Berikut pada Gambar 2 dari prinsip kerja peralatan.

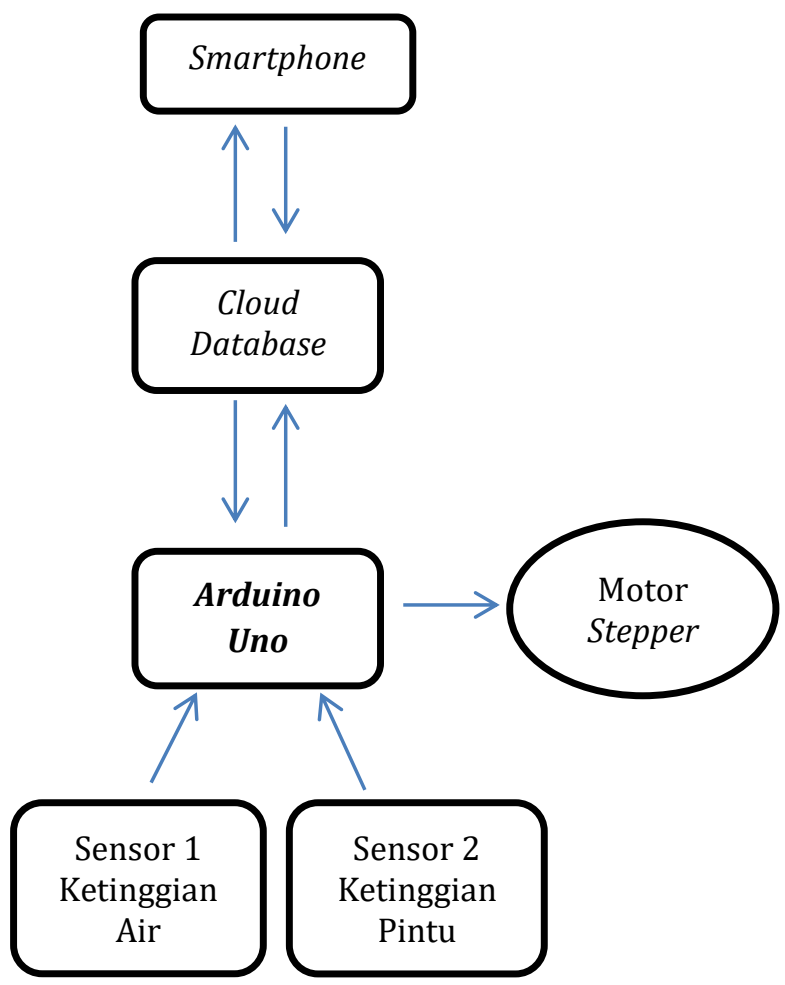

Gambar 2. Prinsip kerja pengendali buka tutup pintu air

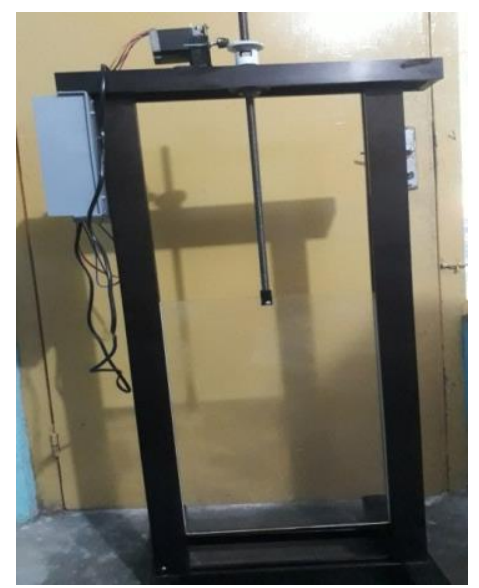

Gambar 3. Miniatur peralatan pengendali buka tutup pintu air dengan bantuan smartphone android

Bahan pada sistem mekanik peralatan pintu air :

1. Hollow Alumunium dengan tebal $1,2 \mathrm{~mm}$

2. Spigot Alumunium

3. Baut rivet

4. Besi pelat sebagai penguat inti alumunium

5. besi ulir panjang $60 \mathrm{~cm}$

6. Roda gigi kerucur

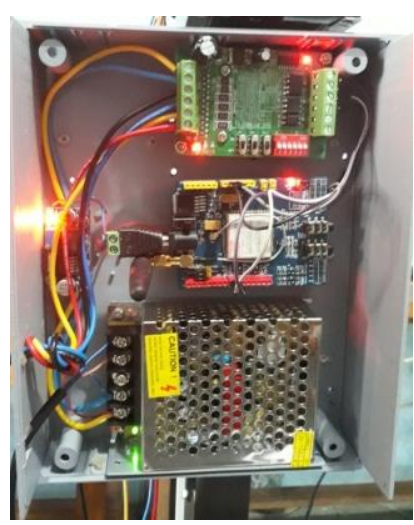

Gambar 4. Peralatan pengendali mikrokontroller Arduino Uno

Peralatan Sistem kendali, di antaranya :

1. Arduino Uno sebagai mikrokontroller program

2. Sensor Ultrasonic HC-SR04/ sensor ping / sensor ultrasonic sebagai sensor debit air

3. Sim900 modul (GSM/GPRS)sebagai modem jaringan internet yang akan terhubung dengan handphone android

4. Driver motor stepper TB-6560 sebagai driver kontrol motor stepper

5. Motor stepper sebagai pengendali sistem mekanik buka tutup pintu air.

6. Catu Daya 5A sebagai supplay tegangan sistem pengendali

7. Kartu GSM

\section{Analisis Pengukuran Tanpa Beban Pintu Air}

Pada percobaan pengukuran besarnya arus dan tegangan tanpa beban. beban yang dimakssudkan dalam hal ini adalah penggunaan motor stepper kerjanya tidak dihubungkan dengan menggunakan pintu air. tabel dibawah ini akan menunjukkan besarnya arus dan tegangan pada kondisi tersebut.

Tabel 1. Pengukuran arus dan tegangan tanpa beban pintu air

\begin{tabular}{ccccc}
\hline \multirow{2}{*}{$\begin{array}{c}\text { Pengukuran } \\
\text { ke-n }\end{array}$} & \multicolumn{2}{c}{ Starting } & \multicolumn{2}{c}{ Nominal } \\
\cline { 2 - 5 }$(\mathrm{A})$ & $\begin{array}{c}\text { Arus } \\
(\mathrm{V})\end{array}$ & $\begin{array}{c}\text { Arus } \\
(\mathrm{A})\end{array}$ & $\begin{array}{c}\text { Tegangan } \\
(\mathrm{V})\end{array}$ \\
\hline 1 & 4.41 & 10.6 & 2.72 & 12 \\
2 & 4.23 & 11 & 2.81 & 12 \\
3 & 4.65 & 10.7 & 2.74 & 11.8 \\
4 & 4 & 11.3 & 2.85 & 12 \\
5 & 4 & 11.2 & 2.8 & 12.3 \\
\hline
\end{tabular}




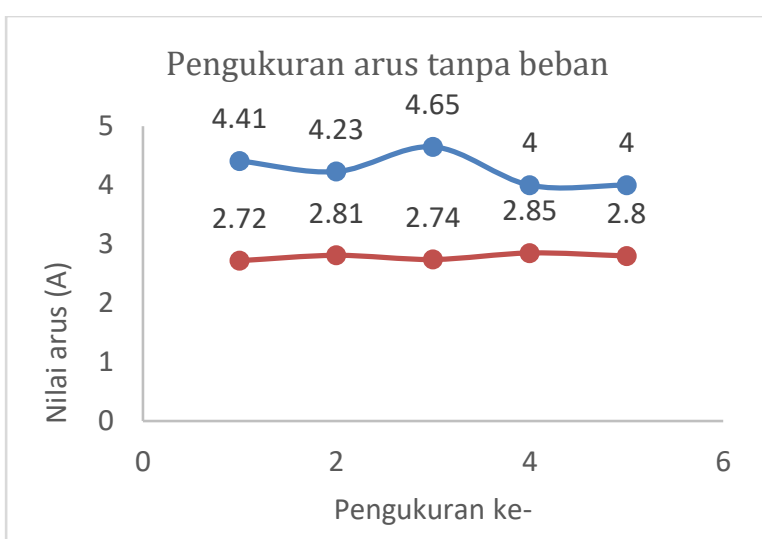

$\longrightarrow$ Arus Starting $\quad \longrightarrow$ Arus Nominal

Gambar 5. Diagram perbandingan arus starting dan arus nominal

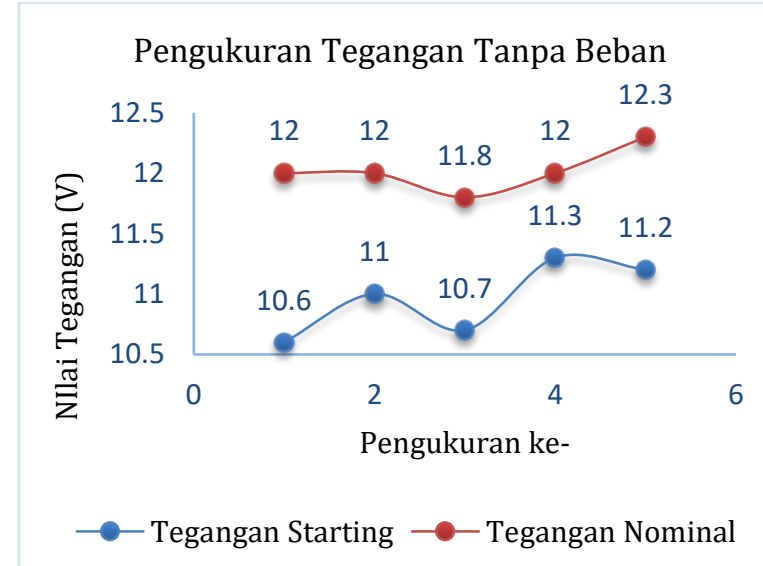

Gambar 6. Diagram perbandingan Tegangan Starting dan Tegangan Nominal

Pengukuran arus dan tegangan starting dilakukan sesaat ketika motor stepper melakukan starting sedangkan pengukuran tegangan dan arus nominal dilakukan pada saat motor stepper kondisi beroperasi. dari data di atas dapat disimpulkan bahwa secara rata-rata arus starting lebih besar daripada arus nominal sedangkan nilai tegangan menyusut ketika proses starting dan akan stabil pada saat motor kondisi nominal. hal ini dikarenakan pada saat putaran motor di awal membutuhkan energi yang lebih besar daripada motor yang beroperasi secara normal

Tabel 2 Pengukuran Dengan Menggunakan Beban Pintu

\begin{tabular}{ccccc}
\multicolumn{4}{c}{$\begin{array}{c}\text { Air } \\
\text { Pengukuran } \\
\text { ke-n }\end{array}$} & \multicolumn{2}{c}{ Kondisi Membuka } & \multicolumn{2}{c}{ Kondisi Menutup } \\
\cline { 2 - 5 } & $\begin{array}{c}\text { Arus } \\
\text { (A) }\end{array}$ & $\begin{array}{c}\text { Tegangan } \\
\text { (V) }\end{array}$ & $\begin{array}{c}\text { Arus } \\
\text { (A) }\end{array}$ & $\begin{array}{c}\text { Tegangan } \\
\text { (V) }\end{array}$ \\
\hline 1 & 3.1 & 11.9 & 2.9 & 12.1 \\
2 & 3.15 & 11.7 & 3 & 12 \\
3 & 3 & 12 & 2.92 & 12.5 \\
4 & 3.23 & 11.8 & 3.01 & 12 \\
5 & 3.17 & 12.1 & 3 & 12.3 \\
\hline
\end{tabular}

\section{Pengukuran Menggunakan Beban Pintu Air}

Pada percobaan pengukuran besarnya arus dan tegangan menggunakan pintu air yaitu motor stepper kerjanya dihubungkan dengan pintu air. Tabel 2 menunjukkan besarnya arus dan tegangan pada kondisi motor membuka pintu air dan motor menutup pintu air.

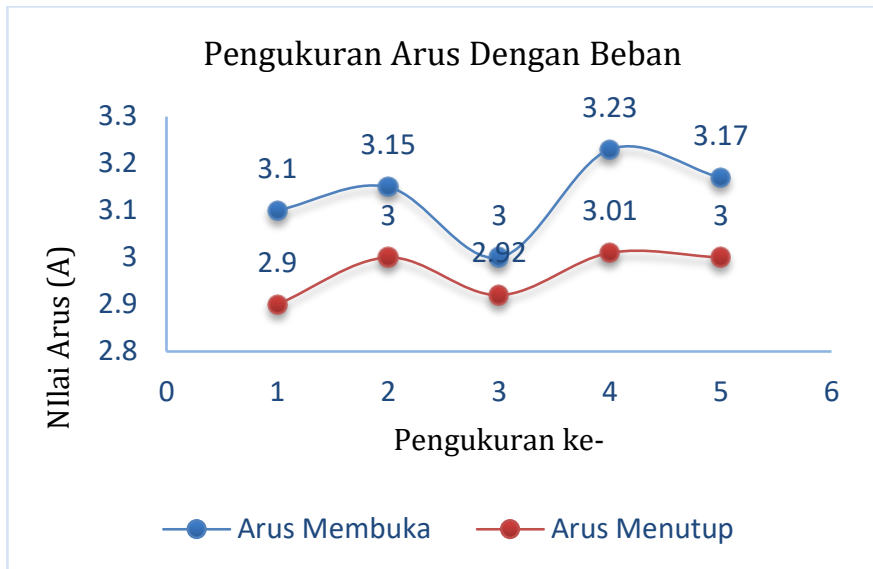

Gambar 7. Diagram perbandingan arus dengan beban

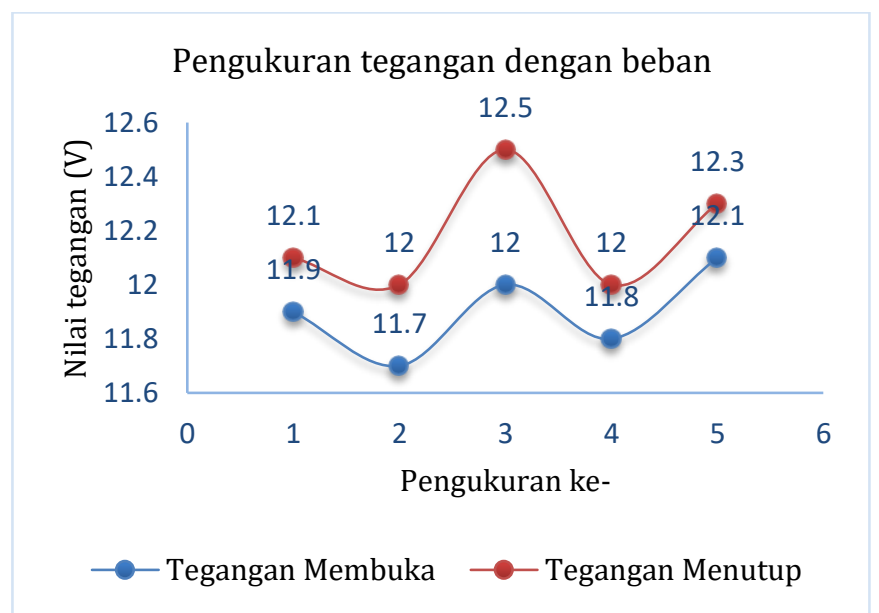

Gambar 8. Diagram perbandingan tegangan dengan beban

\section{Analisis Data}

Dari data pengujian diatas bertujuan untuk mengetahui perbedaan arus dan tegangan pada saaat membuka dan menutup pintu air. Hal ini dapat diketahui bahwa kondisi arus ketika membuka pintu air mempunyai nilai yang besar daripada nilai arus nominal motor stepper. sedangkan nilai tegangannya konstan. Hal ini dikarenakan pada saat kondisi membuka pintu air motor stepper menerima beban yaitu pintu air sehingga secara sistem maka arus dari motor tersebut akan meningkat.

\section{Analisis Rangkaian}

Berdasarkan penelitian (Silvia, Haritman, \& Mulyadi, 2014), pengukuran dan pengujian sistem kontrol pintu gerbang berbasis arduino dan android, memiliki kelebihan pada fitur hubungan 
smartphone sistem android melalui koneksi Bluetooth untuk membuka dan menutup gerbang secara otomatis. Hardware dan software berfungsi dengan baik, dimana mampu beroperasi sesuai dengan program dan perintah yang dimasukkan. Sementara pada penelitian ini pengaruh dari perubahan nilai arus peralatan pengendali, maka program arduino uno juga terpengaruh maka dalam mengantisipasi perubahan nilai arus yang signifikan ini maka digunakan diode dengan reverse, sehingga perubahan arus dan pengendali arduino uno dapat diminimalisir. Keluaran tegangan arduino uno dan peralatan motor stepper 5V DC maka dibutuhkan power supply yang mempunyai nilai arusnya sangat besar karena digunakan untuk mensuplai semua peralatan tersebut.

Pada pengujian aplikasi Makassar Tourism pada kota Makassar yang berbasis android menjelaskan bahwa koneksi internet yang buruk mempengaruhi kinerja aplikasi, seperti load data pada list view, upload foto add tempat, load gambar pada gallery (Setiawan, Andjarwirawan, \& Handojo, 2013). Pada rangkaian penelitian ini kelancaran sistem kerja terpengaruh pada koneksi jaringan internet dan hubungan interface antara smartphone android dengan peralatan pengendali dibutuhkan cloud yang berfungsi penyimpanan database eksternal. Hal ini dikarenakan dalam arduino uno tidak menyediakan ruang penyimpanan database. Hal ini berpengaruh terhadap respon peralatan pengendali terhadap smartphone.

\section{PENUTUP}

Perbedaan arus dan tegangan pada saat awal dan kondisi berjalan tidak signifikan dan tidak mempengaruhi kinerja buka-tutup pintu air. Peralatan pengendali arduino uno tidak menyediakan ruang dalam pengelolaan database secara online, maka dibutuhkan software pendukung lainnya untuk mengatasi hal tersebut. Sistem arduino uno sebagai pengendali dan aplikasi pada smartphone sistem android sebagai media informasi yang memberikan sumber informasi yang bersifat terbuka.

Saran pada pembuatan aplikasi android dan pengelolaan database ini dapat menggunakan bantuan web yang tidak berbayar.

\section{DAFTAR PUSTAKA}

Direktorat Kehutanan Dan Konservasi Sumber Daya Air. (Desember 2012). Analisa Perubahan Penggunaan Lahan Di Ekosistem DAS Dalam Menunjang Ketahanan Air Dan Ketahanan Pangan, Studi Kasus: DAS Brantas. Jakarta: BAPPENAS.

Guntoro, H., Somantri, Y., \& Haritman, E. (2013). Rancang Bangun Magnetic Door Lock Menggunakan Keypad Dan Solenoid Berbasis Mikrokontroler Arduino Uno. ELECTRANS, Vol.12, No.1, 39- 48.

Kementerian Kehutanan, Badan Penelitian dan Pengembangan Kehutanan. (2012). Sistem Perencanaan Pengelolaan Daerah Aliran Sungai. Bogor: Pusat Penelitian dan Pengembangan Konservasi dan Rehabilitasi (P3KR).

Setiawan, I., Andjarwirawan, J., \& Handojo, A. (2013). Aplikasi Makassar Tourism Pada Kota Makassar Berbasis Android. Jurnal Infra, 1, 156.

Silvia, A. F., Haritman, E., \& Mulyadi, Y. (2014). Rancang Bangun Akses Kontrol Pintu Gerbang Berbasis Arduino Dan Android. ELECTRANS, VoL.13, No.1, 1-10.

Wibowo, S. H. (2014). Simulasi Pengontrolan Pintu Garasi Otomatis. INTEKNA, Tahun XIV, No. 2, $102-109$ 
A Kusumawardhani, dkk / Teknika : Engineering and Sains Journal, Vol. 1, No.2, Desember 2017, 89-94

Halaman ini sengaja dikosongkan 